\title{
Society of Chemical Industry: Annual Meeting and Congress of Chemists.
}

SINCE its foundation in I88I, the Society of Chemical Industry has held its annual meeting in one or other of the many geographical centres where its sections are located. This year's meetingthe forty-fifth-was held in London on July 19-23, and differed from all previous meetings in taking the form of a congress of chemists, no fewer than seventeen chemical organisations taking part in it. For this reason, everything was done on an unusually large scale, and save for the physical weariness which inevitably follows from such an orgy of conferences, dinners, excursions, and social functions, the week must have been one of unmitigated profit and enjoyment to the very large number of chemists and their friends who attended.

The United States was well represented by Drs. F. G. Cottrell and E. Hendrick, Mr. T. H. Norton, and Profs. J. Kendall, H. R. Moody, and R. Stevenson; Profs. P. Sabatier and E. Fourneau came from France, Dr. J. P. Arend from Luxembourg, Prof. L. F. Goodwin from Canada, and Prof. K. Matsubara from far Japan. The Hotel Great Central made an excellent headquarters, its spacious rooms and lounges providing all the accommodation required, whilst the exhibitions of chemical plant and of chemical apparatus were shown at the Central Hall, Westminster, and at the Institute of Chemistry, respectively, and club facilities were generously provided by the Chemical Industry Club in Whitehall Court. Nothing but praise is due to those who were responsible for the general organisation, and the president, Mr. W. J. U. Woolcock, the chairman of the London Section and the Chemical Engineering Group, Mr. C. S. Garland, and the general secretary, Dr. J. P. Longstaff, must have been gratified at the undoubted success which attended their efforts.

For the first time in the history of the Society, an organised attempt was made, through the agency of a publicity committee, to interest the lay as well as the technical press, and although competition for 'space' was severe owing to the vagaries of the franc, the meeting of the British Medical Association at Nottingham, and innumerable sporting events, the results obtained were very encouraging. The presence of H.R.H. the Duke of York, the Earl of Balfour, and the Lord Mayor on the opening day made an excellent lever $d u$ rideau, whilst the speeches of Sir Alfred Mond at the conference on hormones and at the Society's annual dinner, the address of Sir Josiah Stamp, who spoke on "The Economics of Monopolies, with particular reference to America," and that of Sir Max Muspratt at the opening of the exhibition of chemical plant, provided the press with favourable opportunities to direct attention to the importance of chemistry through the mouths of well-known public men.

The increasing growth of the chemical industry proper is a fact that was emphasised by several speakers, but of even more significance is the manner in which chemistry has penetrated into a large number of industries which are not specifically chemical. No body is more suited to advance the welfare of chemistry in industry than the Society of Chemical Industry. In recent times many smaller societies, essentially chemical in nature, have been formed to serve the needs of branches of applied chemistry, but this Society is in a sense the mother of all, and although it has suffered from the competition of these smaller communities, and is still feeling the full blast of financial stringency, there yet remains to it a most important sphere of influence in co-ordinating the activities of all societies devoted to the advancement of applied chemistry. Substantial progress has been made in this direction during the past two years: joint conferences and joint social functions have become the order of the day, and a valuable step forward has been made in the formation of a Fuel Section of the Society.

This centripetal tendency within the industry and profession of chemistry is well shown in the project to establish a central home for chemistry in London, which was taken up by the Federal Council for Pure and Applied Chemistry some six years ago, but, unfortunately, has been held up for financial reasons. The subject was discussed at a special meeting of the Congress, but no solution was found. One group favours a policy of 'masterful inactivity' until the industry is in a position to subscribe a sum of the order of $250,000 l$. for acquiring a home large enough to house the offices of existing societies, and to provide accommodation for large meetings, a library, and a club. The other group is weary of waiting and would embark upon a much smaller scheme involving the expenditure of $35,000 \mathrm{l}$ - $-40,000 \mathrm{l}$. If such a sum could be raised, the latter scheme would appear preferable, provided that it were carried out in such a way as not to exclude the ultimate realisation of the more ambitious project.

Concurrently with a conference on hormones (see p. I74 of this issue), a symposium on corrosion was held under the auspices of four societies. Mr. U.R. Evans led off with an able summary of the main facts and hypotheses connected with the corrosion of metals by air and by chemical agents. He was followed by Dr. W. H. Hatfield with a paper on resistant steels for chemical engineering, in which were described the action of various chemicals on chromium steels (I2-I4 per cent. chromium) and on a nickel-chromium steel (I 8 per cent. chromium, 8 per cent. nickel); the latter steel is now used extensively in chemical manufacture. A similar subject was treated by Messrs. T. G. Elliot and G. B. Willey, who outlined the properties of certain Hadfield steels that are remarkably resistant at very high and very low temperatures. Two papers by Mr. P. Parrish completed the series, the first dealing with the corrosion and erosion of plant used in the manufacture of ammonium sulphate at gas and coke-oven works, and the second with the corrosion and erosion of chemical sheet-lead.

Among the most interesting and best-delivered contributions were those by Dr. W. R. Ormandy in connexion with power alcohol. In the first he described the development of a process for making glucose from waste wood, by which the cellulose of dried sawdust is treated with concentrated hydrochloric acid and converted into hexose sugars $(92$ per cent.) and pentose sugars ( 8 per cent.) Very many technical difficulties impeded the elaboration of the process, not the least of which was to find a material capable of withstanding the action of the acid. The material now successfully used ('Prodorite') is a high-melting pitch mixed with mineral matter of carefully graded particle-sizes; it shows no tendency to 'creep,' behaving like a solid up to $125^{\circ} \mathrm{C}$. About $250,000 l$. has been expended in elaborating the process, which is now a technical success, and it is hoped to produce large quantities of high-grade glucose together with inferior sugar suitable for conversion into alcohol. As about 20 per cent. of all timber hewn is lost as waste wood, it is obvious that there is great scope for this process in such countries as Canada and Scandinavia.

In their paper on " Experiences with Alcohol Motor 
Fuels," Dr. Ormandy and Mr. D. Ross dealt with the use of alcohol as a motor fuel when mixed with petrol or benzol. Alcohol has the great advantage that it allows the use of a much higher compression ratio in the engine than petrol or any constituent of petrol, thereby obviating premature detonation (' pinking '). Commercial (95 per cent. vol.) alcohol does not mix well with petrol, but now that alcohol can be easily and economically dehydrated by distilling azeotropic mixtures, this difficulty has disappeared. Road tests carried out by the London General Omnibus Co. using petrol with a small proportion of 99 per cent. alcohol, and a mixture of 65 per cent. denatured alcohol, 30 per cent. benzol, and 5 per cent. ether gave quite satisfactory results and showed that, owing to its anti-detonating action, alcohol can advantageously be added to low-grade petrols to improve their value.

The great importance of the size of particles of pigment and compounding powders used in the paint and rubber industries, was discussed at a conference presided over by Sir William Bragg. After Dr. D. F. Twiss and Mr. C. A. Klein had outlined the main problems, specialised papers were read by Dr. S. S. Pickles, Dr. P. Schidrowitz, Mr. T. R.
Dawson, Mr. Nöel Heaton, Mr. E. A. Murphy, Mr. H. Green (U.S.A.), and by Messrs. G. Gallie and B. D. Porritt. At the concluding sessions Mr. L. J. Simon and Prof. J. W. Hinchley contributed a paper on fat-extraction by solvents, in which they described a new large-scale process for extracting fat from seeds which involves a very short period of extraction, economy in the consumption of solvent, and low capital cost; and Dr. E. W. Smith presented a very useful summary of recent discussions concerning solid smokeless fuel. Low-temperature processes, said the author, are at present both technically and economically unproven and the immediate problem consists in improving hightemperature coke for industrial and domestic uses. Such coke must be dry, and contain as low an ashcontent as is compatible with economic production. It must be suitably graded, and the grades standardised.

The attendance at all the conferences was very good, and the papers were of a high standard, although there were so many of them that little time was left for discussion. Considered as a whole, the meeting was remarkable not only for its magnitude, but also for the diversity and interest of the subjects discussed.

\section{The Commercial Production of Hormones.}

$\mathrm{A}^{\mathrm{T}}$ a joint meeting of the Biochemical Society and the London Section of the Society of Chemical Industry on July 20, a series of papers on "The Scientific and Industrial Problems presented by the Hormones-the Natural Drugs of the Body," was read. The chair was taken by Sir Alfred Mond, who, in the course of his introductory remarks, referred to the work done by the British school on this subject and to the success which has followed the co-operation of the biochemist, the manufacturer and the physiologist, especially in the commercial production of insulin. The financier, though doubtless an essential member of the team, should occupy a subsidiary position to the research worker. Dr. H. H. Dale followed with a paper on the experimental study and use of hormones; Dr. H. W. Dudley described the chemistry of the pituitary gland and of insulin, and Mr. F. H. Carr the commercial production of hormones; Dr. H. A. D. Jowett gave an account of the history of adrenaline, and Prof. G. Barger discussed the recent progress in the chemistry of thyroxine. Dr. J. W. Trevan's paper on the biological assay of hormones was not read, but in the following account of the main parts brought out by the various speakers, use has been made of an abstract with which we have been furnished.

Only one of the hormones has, so far, been synthesised in the laboratory. Although the presence of a pressor principle in the suprarenal gland was first shown by Oliver and Schafer in 1894, it was not until I9or that it was obtained in the crystalline state by Takamine, who, with greater courage than was shown by previous investigators, added strong ammonia in excess to the purified aqueous extract of the gland and so precipitated the base. In the same year Aldrich assigned it the formula $\mathrm{C}_{9} \mathrm{H}_{13} \mathrm{O}_{3} \mathrm{~N}$, and this was afterwards confirmed: its structure was definitely proved by Jowett in 1904, who, by exhaustive methylation and subsequent oxidation, obtained veratric acid and trimethylamine, and about the same time the compound was also synthesised by Stolz. The synthetic product was of course the racemic form : in I908 Flacher separated the dextro- from the lævo- variety, by treating the bitartrate with methyl alcohol, which dissolves the former and leaves the latter behind. The pressor effect of the lævo- naturally occurring form is fifteen times greater than that of its isomer.

Although the chemist may have finished with adrenaline, to the biochemist and physiologist it is still the central figure in many unsolved problems. How does the body make it? What is its function under ordinary conditions of life? To the first question there is as yet no answer: to the second a tentative reply may be given, but it is a curious fact that, although adrenaline has so simple a chemical constitution, and such a powerful physiological action when injected, yet its presence in the body under ordinary conditions, except in the suprarenal glands themselves, has been extremely difficult to demonstrate satisfactorily: in fact it has even been denied that it has any function in ordinary circumstances. It is probable, however, that it plays a part in the maintenance of the tone of the small blood-vessels, and also is secreted into the blood stream in larger quantities under conditions of emotional and physical stress.

It is interesting to contrast with the history of adrenaline that of thyroxine. The administration of thyroid gland in myxœedema was the first example of a successful substitution therapy: it is still the main example of this type of treatment, and, excepting possibly the oxytocic principle of the pituitary gland, the only example of a successful result being obtained by administration by the mouth. It is stated to have been used in China for this purpose more than a thousand years ago. But the active principle was not isolated until a few years since, when Kendall was successful in preparing it. Within the last year Harington has been able to synthesise desiodo-thyroxine, the compound formed when the iodine is removed from the molecule of thyroxine. An account of Harington's work has been recently given in these columns (July Io, p. 65), so that it will not be further discussed here: it may be assumed that the final synthesis is now only a matter of time.

The commercial production of other hormones, of which the chemical constitution is unknown, requires the supervision of skilled chemists in the process of manufacture, and the co-operation of the research biochemist in the improvement of existing processes 